\author{
SERIES "CONTRIBUTIONS FROM THE EUROPEAN RESPIRATORY MONOGRAPH" \\ Edited by M. Decramer and A. Rossi \\ Number 8 in this Series
}

\title{
The public health relevance of air pollution abatement
}

\author{
N. Künzli
}

\begin{abstract}
The public health relevance of air pollution abatement. N.Künzli. (C)ERS Journals Ltd 2002

ABSTRACT: Assuming a causal relationship between current levels of air pollution and morbidity/mortality, it is crucial to estimate the public health relevance of the problem. The derivation of air pollution attributable cases faces inherent uncertainties and requires influential assumptions. Based on the results of the trinational impact assessment study of Austria, France, and Switzerland, where prudent estimates of the air pollution attributable cases (mortality, chronic bronchitis incidence, hospital admissions, acute bronchitis among children, restricted activity days, asthma attacks) have been made, influential uncertainties are quantified in this review.

The public health impact of smoking, environmental tobacco smoke, and air pollution on the prevalence of chronic cough/phlegm are outlined. Despite all methodological caveats, impact assessment studies clearly suggest that public health largely benefits from better air quality. The studies are selective underestimates as they are strongly driven by mortality, but do not include full quantification of the impact on morbidity and their consequences on quality of life among the diseased and the caregivers.

Air pollution abatement strategies are usually political in nature, targeting at policies, regulation and technology in mobile or stationary sources rather than at individuals. It is of note that key clean air strategies converge into abatement of climate change. In general, energy consumption is very closely related to both air pollution and greenhouse gases. The dominant causes of both problems are the excessive and inefficient combustion of fossil fuel. Thus, for many policy options, the benefit of air pollution abatement will go far beyond what prudent health-impact assessments may derive. From a climate change and air pollution perspective, improved energy efficiency and a strong and decisive departure from the "fossil fuel" combustion society is a science-based must. Health professionals must raise their voices in the political decision process to give strong support for clean air policies, both on a national and international level.
\end{abstract}

Eur Respir J 2002; 20: 198-209.

\author{
N. Künzli, Institute for Social and \\ Preventive Medicine, \\ Basel University, \\ Switzerland.
}

Correspondence: Nino Künzli

Institut für Sozial- und Präventivme-

dizin der Universität Basel

Steinengraben 49

4051 Basel

Switzerland

Fax: 41612676190

E-mail: Nino.Kuenzli@unibas.ch

Keywords: Air pollution

clean air regulation

health-impact assessment

PM10

population attributable risk

Received: March 182002

Accepted: March 182002

The author is a recipient of a National Science Foundation Advanced Scientist Fellowship (\#3233-048922.96/1).
Whereas resources for prevention and treatment are restricted, the growth in scientific knowledge has no limitation. Due to unprecedented developments in science and technology during the last decades, many health and disease processes can be explained, even on the level of genes, proteins and cells. The availability of powerful processors to handle very large amounts of data and the development of highly sophisticated study designs and biostatistical tools [1, 2], made it possible to observe, with high precision, the association between the variability of ambient air pollution and the daily number of hospital admissions and death [3]. Consistent with European findings [4], e.g. the recent USA study of SAMET et al. [3] reported a small, but significant $(\sim 0.1-1.0 \%)$, increase in daily death counts per $10 \mu \mathrm{g} \cdot \mathrm{m}^{-3}$ increment in particulate mass collected by a convention with a $50 \%$ efficiency for ambient particles with an aerodynamic diameter of $<10 \mu \mathrm{m}$ (PM10). State of the art multivariate analyses of scientific data offered the opportunity to reliably estimate minute differences in risk across subgroups of varying risk profiles. For example, in the Swiss Study on Air Pollution and Lung Diseases (SAPALDIA), LEUENBERGER et al. [5] observed an adjusted increase of $65 \%$ in the risk of chronic bronchitis symptoms among nonsmokers exposed to passive smoking compared with those without passive smoking. In the same data set, an increase in the long-term mean

Previous articles in this series: No. 1: Baldacci S, Omenaas E, Oryszcyn MP. Allergy markers in respiratory epidemiology. Eur Respir 2001; 17: 773-790. No. 2: Antó JM, Vermeire P, Vestbo J, Sunyer J. Epidemiology of chronic obstructive pulmonary disease. Eur Respir J 2001; 17: 982-994. No. 3: Cuvelier A, Muir J-F. Noninvasive ventilation and obstructive lung diseases. Eur Respir J 2001; 17: 1271-1281. No. 4: Wysocki M, Antonelli M. Noninvasive mechanical ventilation in acute hypoxaemic respiratory failure. Eur Respir J 2001; 18: 209-220. No. 5: Østerlind K. Chemotherapy in small cell lung cancer. Eur Respir J 2001; 18: 1026-1043. No. 6: Jaakkola M.S. Environmental tobacco smoke and health in the elderly. Eur Respir J 2002; 19: 172-181. No. 7: Hollings N, Shaw P. Diagnostic imaging of lung cancer. Eur Respir J 2002; 19: 722-742. 
ambient particulate matter concentration (PM10) was associated with a $27 \%$ higher probability to report chronic bronchitis symptoms [6] and with, on average, a 3\% lower forced expiratory capacity [7].

Although toxicology, molecular science and epidemiology greatly increase knowledge on air pollution and health [8], they do not, by default, answer the question whether any or all the described, postulated, or observed associations and mechanisms are relevant. From a public health and decision makers' perspective it is, however, crucial to consider the relevance of health problems to efficiently allocate the limited resources to protect and enhance the health of the public. In this review, the challenge as to how to assess the relevance of air pollution objectively will be discussed. Given the uncertainties of such assessments, the most influential methodological assumptions in the derivation of relevance will be highlighted and quantified with examples. The third section presents a comparative assessment of the relevance of three important respiratory health hazards: smoking, environmental tobacco smoke (ETS) and air pollution. In the last section, major air pollution abatement strategies will be summarised and it will be discussed whether health benefits can truly be expected.

\section{Attributable cases: an objective measure of relevance}

The relevance of risks may be judged from many different perspectives. Table 1 lists some major

Table 1.-Major criteria in judging the public health relevance of environmental exposure

Domain of Criterion

judgement

Exposure

Abatement/ prevention
Probability of exposure

Intensity of exposure

Frequency of exposure

Duration of exposure

Life period of exposure

Number of people exposed

Degree of choice (voluntary exposure?)

Benefit of source that causes the exposure

Type of health effect

Degree and intensity of effect

Size of effect (e.g. relative risk)

Specificity of effect (other causes?)

Acute versus chronic effect

Frequency of health outcome among nonexposed

Reversibility of effect

Acceptance of effect

Costs of effects

Number of susceptible among exposed

Feasibility of abatement strategies

Costs of abatement

Benefits of abatement

Specificity of the abatement strategy

Reversibility of health problems

Time of benefit of abatement

Acceptance of abatement strategy

Level of abatement (e.g. individual behaviour versus structural) criteria in evaluating the public health relevance of environmental exposures such as air pollution. Several criteria are subjective or political in nature, thus, a value matter. Some aspects, however, are rather objective quantitative measures. Epidemiological research investigates health effects under true living conditions. Therefore, results of epidemiological studies provide useful objective measures to derive one aspect of relevance: the number of cases (or the proportion of all cases) attributable to air pollution. In a next step, these cases may be monetarised to estimate the costs of the health impact [9-11]. However, economic methods may also include judgement values, thus, it is useful to separate objective quantitative and subjective or qualitative assessments of relevance clearly. Attributable cases as an example of objective measures of relevance are the focus of this review.

Conceptually, the assessment of the air pollution attributable cases is straightforward and relies on the widely used calculation of "population attributable risk" and "population attributable proportions" [12]. In contrast to risk measures such as the relative risk (RR) or the regression slope, which quantify the risk for an individual, given some exposure compared with no (or lower) exposure, the "attributable risk" also includes the number of people exposed or the exposure distribution in the population. The estimates are considered to reflect the cases or proportion among all cases explained by one specific factor. Thus, the measure is appealing for judging the public health relevance of a health problem. For example, extremely rare exposures with very high RRs may be of minor public health importance compared with a hazard of small risk but with large fractions of the population being exposed [13]. The application of attributable risk methods to air pollution has been extended by KRZYZANOWSKI [14] of the World Health Organisation (WHO) Europe and KüNZLI et al. [15], as well as in national and international studies [16].

Figure 1 shows the calculation model with the main information needed to estimate the number of cases attributable to air pollution in a given population. Summary results of one example of estimating the air pollution attributable cases are given in table 2 .

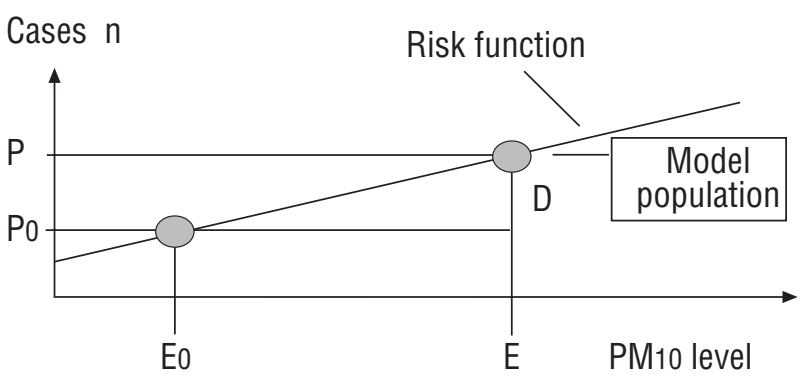

Fig. 1.-Model to derive number of air pollution attributable cases. The risk function (response function, slope, relative risk), population frequency of the health outcome $\mathrm{P}$ (prevalence, incidence, number of days, etc.), and the population weighed exposure $\mathrm{E}$ (or concentration) are needed to calculate $\mathrm{D}$, the total number of attributable cases. An exposure reference level (E0), below which health effects are ignored, must be defined. $\mathrm{P}_{0}$ is the outcome frequency, given exposure E0. 
The methods are described in the respective reports and publications of the trinational study, initiated by WHO Europe and conducted for the governments of Austria, France, and Switzerland [9, 10, 15, 17, 19]. Ideally, for each target population, the concentration/ response or risk function, the distribution of ambient exposure (or concentration) in the population (E0 in fig. 1) and the frequency of the considered health outcome $(\mathrm{P})$, e.g. death rates or the incidence of chronic bronchitis symptoms, would be needed. However, these data are usually not fully available, thus, the impact assessment requires transfer of estimates and generalisation of findings from one population to another population. Due to inherent uncertainties and differences in the underlying assumptions of the calculation process, impact assessment studies are often not directly comparable and open to debate. A formal quantification of the uncertainty, although preferred by decision makers, may not resolve the problem but pretend a degree of precision which has no scientific ground. Thus, impact assessors may choose sensitivity analyses or different scenarios [20]. In contrast to toxicology-based risk assessments of toxic substances, where large margins of safety are usually included, "worst case scenarios" may not be informative for epidemiology-based air pollution impact assessment. It may be more useful to make prudent assumptions, wherever required, to estimate "at least" the cases attributable to air pollution, thus, to most likely underestimate the true size of the problem $[9,15]$. Influential uncertainties relate to the issue of causality, the choice of the concentration/response function, the definition and reference level of air pollution, the background frequency of diseases, and the quantification and interpretation of mortality studies. The current initiative of the European office of WHO is a useful step to develop methodological guidelines for air pollution health-impact assessment [21, 22].

\section{Causality}

The assessment of the impact of air pollution inherently assumes that air pollution causes morbidity and mortality. As discussed in the WHO working group report [21], "causality" is not a clear-cut definition but a process, evaluating the entire scientific evidence. It includes a comprehensive identification of all relevant studies and a systematic assessment of their quality. Conclusions and interpretations must be based on the entire body of valid research. So far, no formal process has been implemented on the general issue of air pollution, although processes such as the development of WHO quality guidelines for Europe have implicitly or partially followed this path [23]. For single pollutants, such as particulate matter or ozone, the USA Environmental Protection Agency's approach of regularly reviewing the literature on criteria pollutants can be considered such a systematic review process. The consideration of formal criteria may be a useful guide to assess the degree of evidence [24]. Whereas some scientists claimed evidence for causality years ago [25], research has since been intensified in many areas of the world. The attempt 
to jeopardise science with politics or to perpetuate misconceptions about epidemiology [26] has failed, and it is of note that scientists made no progress in dismantling the claim for evidence of a causal association between current levels of air pollution and morbidity and mortality in the public [3, 27-29]. Over recent years, the evidence for causality, particularly regarding short-term effects, has become stronger [30].

Although most air pollution experts may claim "causality", the level of evidence may vary for different health outcomes. Thus, impact assessors may need to choose a restricted set of outcomes to derive attributable cases. Depending on where to draw this line, different projects may include different outcomes. In general, much less research has been undertaken to assess the long-term effects of air pollution. Thus, whereas most impact studies may include hospital admissions, asthma attacks or acute respiratory symptoms, the long-term effect on death rates or years of life lost and chronic bronchitis remain more controversial. Studies, such as the USA assessment by Ostro and Chestnut [31], the trinational study [15], or the Italian air pollution project (ITARIA) [32], included chronic bronchitis among adults, based on the Californian Seventh Day Adventist study [33]. However, it is not yet clear whether these air pollution attributable cases may be of the same average severity as chronic bronchitis cases among smokers. Although this uncertainty may be of limited importance in the derivation of attributable cases, in a cost assessment, severity might be of relevance.

\section{Cost of effects}

In general, it is true that the process of cost attribution to the number of cases adds a large level of uncertainty $[9,10,34]$. This is only partly due to the lack of data in the field of health economics but is much driven by the wide margin of cost estimates for mortality. Depending on methods and concepts, the cost of one death may vary by a factor of $>20$. For example, whereas in USA studies a death may be valued up to $\$ 10$ million $[20,35]$, the trinational study used a value of $€ 0.9$ million ( $€ 1.0$ is equivalent to approximately USA $\$ 0.9$; table 2) [9], the UK Department of Transport a value of $€ 1.2$ million [11], and the first Swiss assessment a value of less than $€ 400,000$ [34]. This introduces a margin of quantitative uncertainty which goes beyond any other aspect of uncertainty. Accordingly, controversies are particularly extensive for economic assessments. Given that economic assessments are strongly driven by national preferences and healthcare systems, cost estimates are usually not transferable. The European trinational study attributed some $€ 600-800$ per capita and year to air pollution-attributed health problems with $75 \%$ due to mortality estimates [9]. The cost values (per case) are indicated in table 2 .

\section{The risk function}

As shown in figure 1, the slope of the risk function is influential. In air pollution research, this function is usually based on epidemiological studies. The parameter is often called "exposure/response" or "dose/ response" although epidemiological studies may measure neither "exposure" nor "dose" in their true sense directly. As in the case of meta-analyses of clinical trials, pooled estimates from several studies may be considered an adequate choice. However, some assessors may prefer to use, if available, local effect functions if the uncertainties in these studies are considered to be smaller than those of transferring results from other places. For most outcomes and regions, estimates may not be available. Accordingly, transferring risk functions from a study population to the target population of the impact assessment may be required. This step carries inherent uncertainties if exposure levels and/or quality of exposure grossly differ in the two populations. Although theoretically of concern, it is of note that the currently available risk functions for outcomes such as hospital admissions or symptoms are rather similar across studies from different regions, i.e. heterogeneity in risk functions may not be the most influential factor.

\section{Mortality: how should the impact of air pollution on death be interpreted?}

From a methodological perspective, mortality is a rather unusual and difficult outcome. Due to the high public attention on this outcome and the strong influence of death on cost assessments (table 2), it remains an important and controversial part of the impact assessment. Two concepts of "death" must be distinguished. On one side, death is an event (count data); on the other side it is the delimiter of survival time or life expectancy. Time-series studies are extremely efficient and powerful means with which to investigate the association of the daily number of death counts and the level of air pollution on that day or a few days before. Highly precise estimates of the association between today's level of air pollution and mortality rates in the next few days are available [3]. In fact, even on a global scale, these estimates are rather consistent [4]. However, these time-series studies have a restricted short-term effect perspective which must be of concern for health-impact assessors. For example, let us assume cases where air pollution may trigger respiratory exacerbation [36] or a myocardial infarction [37]. It may well be that some of these cases will survive the very first days but will die within a few weeks, due to this primary, air pollution-related event. Time-series mortality studies will not attribute such "late-onset death" because the vast majority of these studies investigate only the associations between air pollution and death which occur within a few days. In fact, Schwartz [38] has shown that the typical time series do not fully capture the short-term effects of air pollution. Furthermore, the time-series approach does not assess life time lost nor does it account for shortening in life expectancy due to long-term cumulative exposure. For example, air pollution may lead to recurrent infections which, in the long run, may result in chronic respiratory symptoms [6, 33]. These conditions are associated with shorter life 
expectancy [39]. Although the actual "event" of dying may not be related to the level of air pollution at death or the few days before death, such premature death should clearly be part of the air pollution healthimpact assessment, otherwise the attributable cases will be, by default, underestimated. Cohort studies, however, directly assess the impact of cumulative air pollution experience on person-time or time-to-death. Although some very short-term, high-exposure victims of air pollution may not be captured in the cohort approach, this design clearly gives a more complete analysis of the problem. Therefore, based on conceptual considerations, the impact assessment may rely on concentration/response functions from cohort studies [16]. The fact that these risk functions are 5-10-times larger, than those observed in time-series studies, may suggest that the "within-days" effects of air pollution on death are only a small fraction of the entire dynamic between air quality and life expectancy. The disadvantage of this choice, however, is the sparse availability of cohort risk functions. To date, there are only three USA studies available [40-42], two of which have been extensively reanalysed [28]. The preliminary confirmative European study has not yet been published [43]. The heterogeneity across these few studies is larger than across time-series estimates, and impact assessments outside the USA may need to assume that the findings apply similarly to other regions. The uncertainties in the attributable death estimates are not quantifiable.

There are two ways to quantify the impact on "mortality". The above-mentioned cohort studies published the RR for death, thus, it is straightforward to estimate the annual number of attributable deaths. As an alternative, the annual years of life lost may be quantified. These estimates are preferable in evaluating the public health relevance because they are sensitive to the age structure of the victims. Assuming cardiorespiratory causes of death, air pollutionattributed death may be, on average, rather old. So far, published studies did not provide estimates of the years of life lost nor the age structure of the premature death, thus, indirect estimates and assumptions must be relied upon, using life tables of the population. The shortening in population mean life expectancy has been estimated to be in the range of $\sim 6$ to $>24$ months for an increase in the annual mean PM10 of $\sim 10 \mu \mathrm{g} \cdot \mathrm{m}^{-3}[10,44,45]$.

\section{The impact of a mixture}

The implications of air pollution being a mixture rather than one toxic substance are different for epidemiological studies and impact assessments. Epidemiological investigations are very versatile in using many surrogate measures of the air pollution mixture, e.g. nitrogen dioxide, particulate matter of various sizes, ozone, sulphur dioxide, carbon monoxide, etc. These pollutants are often correlated in time and/or space as they share common sources. The best surrogate measure for epidemiological research would be one that: 1) directly is, contains, or is highly associated with the biologically "causal agent"; 2) is geographically homogeneously distributed within a city, thus, a few monitoring stations can efficiently describe the "true" concentration; and 3) the indoor/ outdoor penetration is high, thus, outdoor concentrations also fully reflect the indoor exposure to outdoor pollutants, i.e. "personal exposure" may be measured by central monitors.

Pollutants are rather different with regard to the second and third characteristics, thus, it remains a challenge of epidemiological studies to rank the biological importance across the single pollutants clearly. Accordingly, although the evidence is very strong that air pollution causes mortality and morbidity, it remains more difficult to allocate these effects to one or the other pollutant. In fact, it may be a scientifically weak or at least overly simplistic model to expect that the health problem of air pollution may be explained by one or a few single pollutants.

For health-impact assessment, however, the correlation of pollutants requires the selection of one or a few surrogate pollutants to derive the attributable cases. The sum of the "impact" of each pollutant will grossly overestimate the contribution of air pollution. PM10 is currently the most often reported surrogate measure in epidemiological studies and, therefore, in the health-impact assessment. Ozone, which is a serious additional pollution and health problem in the summer, may be used as a further surrogate to estimate the impact of the oxidant pollution separately.

As shown in the model (fig. 1), population-weighed exposure data are required. In many areas of the world, this might be a formidable challenge due to the lack of monitoring networks. Systematic air pollution monitoring ought to be implemented on a regular basis in all populated areas, otherwise health-impact assessments may be rather speculative.

\section{Impact above what level of pollution?}

The choice of the air pollution reference value (E0 in fig. 1) is of major influence for the number of cases attributed to air pollution. This choice may depend on the purpose of the study. In many countries, policy makers currently face the problem that air quality criteria regulations are intended to "protect health", including the health of the most vulnerable people; to date, research has failed to obtain any evidence for a no-effect threshold. Thus, similar to carcinogens, the natural "threshold" might be zero exposure. Therefore, nonzero target values of clean air acts, inherently assume that some health impact of air pollution may be accepted. Impact assessors must choose a level below which they explicitly want to ignore the impact on air pollution. To demonstrate the influence of this choice, figure 2 shows a model of the air pollution attributable proportion of chronic bronchitis (incidence) in adults as a function of the choice of "exposure reference level". The model uses the data and additive attributable case functions used in the trinational study [15]. Considering zero exposure, i.e. the full impact of air pollution, $>20 \%$ of cases would be attributed to air pollution. However, the attributable proportion above the Swiss clean air act value 


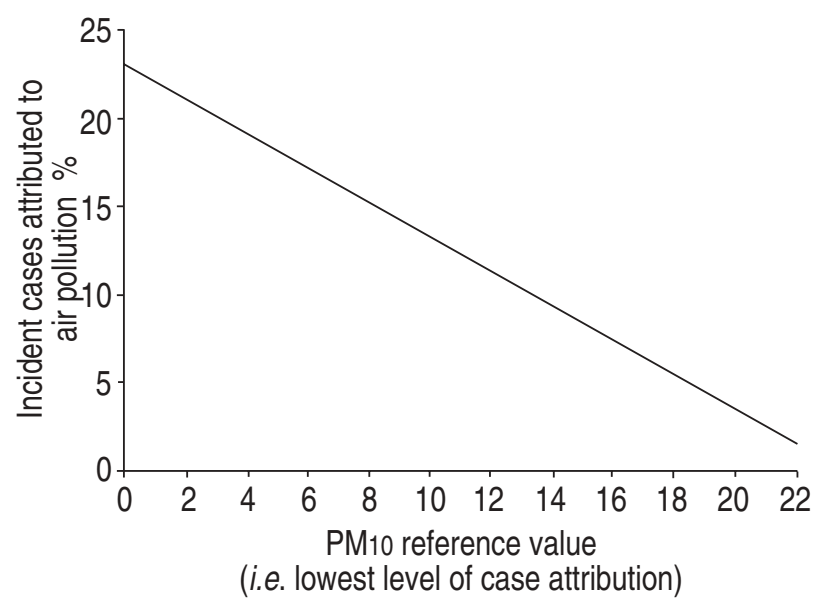

Fig. 2.-Influence of the choice of exposure reference level E0 on the attributable proportion of cases. Health consequences of exposures below the reference value are ignored. Modified from trinational study [19], with a current population-weighed mean of $\sim 24 \mu \mathrm{g} \cdot \mathrm{m}^{-3}$ particles with an aerodynamic diameter of $<10 \mu \mathrm{m}$ (PM10).

(20 $\mu \mathrm{g} \cdot \mathrm{m}^{-3}$ PM10 annual mean) would be well below $5 \%$. The trinational WHO study chose $7.5 \mu \mathrm{g} \cdot \mathrm{m}^{-3}$ (mean of exposure category $5-10 \mu \mathrm{g} \cdot \mathrm{m}^{-3}$ ) to reflect some "natural background" level of air pollution. Given that impact assessments have rather different purposes and may need to address specific policy questions, investigators have used very different values so far $[9,31,32,46,47]$. Therefore, studies cannot be compared directly, even in cases where the methodological framework may otherwise be the same.

\section{The background frequency of diseases matters}

The influence of the background incidence or prevalence of the health outcome in the impact assessment target population may be substantial ( $P$ in fig. 1). Given that the calculation of attributable cases applies, in a first step, the RR function to the background frequency level $P$ suggests that the number of attributable cases is clearly influenced by this value. Unfortunately, many health outcomes are not monitored on a population level and are often poorly defined. For example, although there is good evidence for an increase in asthma attacks among adults during days with increased air pollution, asthma attacks are not monitored and definitions of attacks vary across epidemiological studies. To demonstrate the influence of $\mathrm{P}$ on the final result, the prevalence of chronic cough and phlegm symptoms are used. Based on the SAPALDIA study [6], a 1.65\% (95\% confidence interval: 1.28-2.16) increase may be assumed in chronic bronchitis symptoms, among those with exposure to ETS [48]. Furthermore, an increase in the annual mean PM10 of $10 \mu \mathrm{g} \cdot \mathrm{m}^{-3}$ was associated with a $1.27 \%(1.08-1.50)$ higher $\mathrm{RR}$ for these symptoms [6]. Based on data from ZEMP et al. [6], a crude RR of 2.4 can be derived for chronic bronchitis symptoms in smokers compared with nonsmokers. With the trinational study attributable risk model and the Swiss baseline data (table 3), $\sim 20,000$ prevalent cases may be attributed to air pollution in France, Austria, and Switzerland overall, at $\sim 7 \%$ prevalence of symptoms (fig. 3). However, if the number of smokers is increased up to $100 \%$, the chronic bronchitis symptom prevalence would be expected to increase to $>17 \%$ [6]. In such a population, the impact model of figure 1 would attribute $>50,000$ cases of chronic bronchitis to the same level of air pollution (fig. 3). Although the background frequency of diseases and health-relevant lifestyles may not be very different across Europe, the problem may become serious for some health outcomes i.e. if findings from mostly Western air pollution studies are applied to impact assessment studies in developing countries that have rather different patterns of morbidity and health hazards, apart from ambient air pollution. For example, in many Asian countries, a large fraction of cases of bronchitis among children may be due to indoor burning of solid fuel for cooking and heating, driving the prevalence of bronchitis [49]. Application of Western air pollution/bronchitis risk functions, derived in regions where indoor combustion is almost nonexistent [50], to the Asian background frequency of acute bronchitis may lead to a large overstimate of the cases attributed to outdoor air pollution. Extrapolations from Western countries to developing regions are particularly prone to such errors. To reduce the risk of false overestimation of the health impact of outdoor air pollution, baseline frequency data from populations with low rates may be used, e.g. those reported in the nonsmoking Seventh Day Adventist study [33]. Furthermore, case attribution calculations can be developed which transfer an attributable number of cases instead of the $\mathrm{RR}$ estimates from the source studies to the target population [51].

\section{Comparing attributable risks of different hazards}

As discussed above, considerable uncertainties are inherent in impact assessment, thus, results give an order of magnitude of the problem rather than a precise absolute measure of relevance. For policy makers it may be useful to apply the same methodological framework to different exposure problems and policy options. Thus, the impact and potential benefits may be comparable, whereas the controversy about the absolute numbers of a single study may become less relevant.

On a global level, the Global Burden of Disease (GBD) approach is a valuable attempt in this direction [52-54]. Cohort studies such as the American Cancer study on air pollution and life expectancy [41] were not available in the first GBD assessment of the global burden of air pollution. The importance of air pollution in mortality has, thus, been underestimated [55]. The GBD approach does not simply assess attributable cases but adds an adjustment depending on disability (disability adjusted life years), adding further uncertainty or subjectivity. Although the GBD is very useful in assessments of major health problems on a global scale, the data are of limited guidance for 


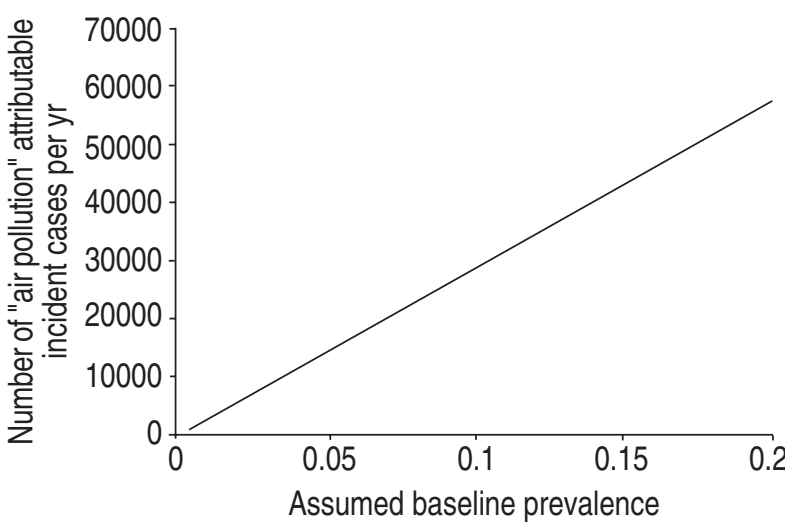

Fig. 3.- Number of cases with chronic cough/phlegm that would be attributed to air pollution depending on the assumed underlying all-cause prevalence in the population.

national or local policy decisions. Applications on a local level are encouraged as they may compare the relevance of different diseases such as the county level example conducted for Geneva, Switzerland [56]. However, to guide policy makers and agencies in decisions concerning allocation of environmental health resources, there is a need for exposure-oriented comparative risk assessments.

For example, a comparison of attributable cases of three hazards may be derived to compare their relevance: smoking, passive smoking, and air pollution. For simplicity, the only health outcome considered will be the prevalence for symptoms of chronic bronchitis [6]. The target population of the example is Switzerland to provide an intrinsically coherent example: concentration/response functions and symptom frequencies are all derived from the SAPALDIA study.

The calculations allow us to compare strategic options in the prevention of chronic cough and phlegm. Table 3 summarises the main parameters with one scenario for each exposure: a $50 \%$ reduction in the smoking prevalence and ETS prevalence among nonsmokers, and a decrease in the population mean PM10 concentration of $10 \mu \mathrm{g} \cdot \mathrm{m}^{-3}$. The expected prevented fraction of these strategies are similar for ETS and PM10 and approximately three-times larger for the smoking scenario. Figure 4 shows the theoretically prevented fraction of separate and combined strategies to reduce these hazards. For example, a 10\% reduction of chronic respiratory symptoms may be achieved: 1) with a reduction of the smoking prevalence from a current $33 \%$ to $\sim 27 \%$; 2) by reducing the prevalence of ETS exposure among neversmokers from currently $13 \%$ to $3 \%$; or 3 ) by a clean air strategy which reduces the annual population mean PM10 from $\sim 25 \mu \mathrm{g} \cdot \mathrm{m}^{-3}$ to $<10 \mu \mathrm{g} \cdot \mathrm{m}^{-3}$. This clean air scenario corresponds approximately to attaining the Swiss target value of $20 \mu \mathrm{g} \cdot \mathrm{m}^{-3}$ PM10 (annual mean). It has been estimated that strategies to achieve this target will shift the population mean to $\sim 10 \mu \mathrm{g} \cdot \mathrm{m}^{-3}$ [57]. In this example, data sources and procedures to derive the attributable cases are intrinsically comparable, thus, regulatory options and costs may be 


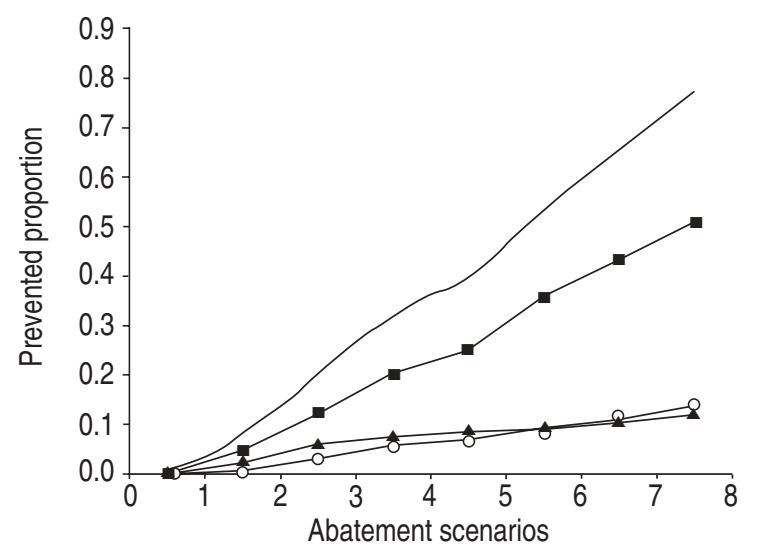

Fig. 4. - Theoretically prevented proportion of chronic cough/ phlegm according to preventive strategies against smoking, environmental tobacco smoke (ETS), and air pollution. Scenario 1: current state (see table 3); scenario 8: removal of exposure. Intermediate scenarios: smoking prevalence $(\boldsymbol{\square})$ for scenario 2-7: 0.3 , $0.25,0.2,0.165,0.1,0.05$, respectively; ETS prevalence $(\bigcirc)$ for scenario 2-7: $0.125,0.1,0.075,0.065,0.5,0.025$, respectively; particles with an aerodynamic diameter of $<10 \mu \mathrm{m}$ (PM10) annual mean $(\mathbf{\Lambda})$ for scenario $2-7: 22.5,17.5,15,12.5,10$, and $5 \mu \mathrm{g} \cdot \mathrm{m}^{-3}$, respectively. $\longrightarrow$ : combined abatement.

assessed in a more coherent manner. Figure 5 shows the expected decline in the symptom prevalence for the same scenario options.

\section{Air pollution abatement to protect public health}

Despite wide margins of uncertainty in the impact assessment procedure, all projects confirm that even

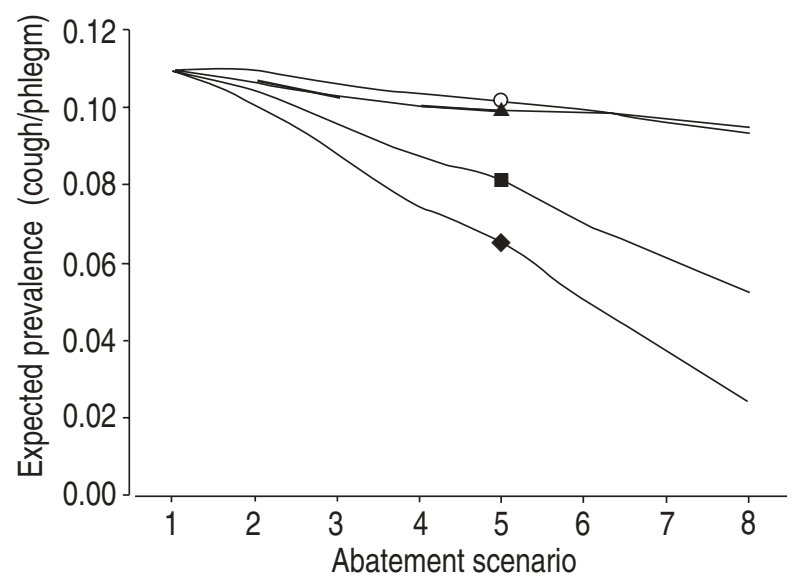

Fig. 5.-Expected prevalence of chronic cough/phlegm under different scenarios of smoking prevalence and environmental tobacco smoke (ETS) among nonsmokers and particles with an aerodynamic diameter of $<10 \mu \mathrm{m}$ (PM10) annual mean reduction strategies. Scenario 1: current state (see table 3); scenario 8: removal of exposure. Intermediate scenarios: smoking prevalence (ם) for scenario 2-7: $0.3,0.25,0.2,0.165,0.1,0.05$, respectively; ETS prevalence $(\bigcirc)$ for scenario $2-7: 0.125,0.1,0.075,0.065,0.5,0.025$, respectively; PM10 annual mean $(\boldsymbol{\Delta})$ for scenario 2-7: 22.5, 17.5, $15,12.5,10$, and $5 \mu \mathrm{g} \cdot \mathrm{m}^{-3}$, respectively; $\diamond$ : combined abatement. Scenario 1 is the current state (Switzerland, according to $[5,6]$ ). under prudent scenarios of an incomplete assessment, air pollution has considerable effects on the health of the public $[9,11,20,32,58,59]$. The comparative example confirms that the mostly voluntary habit of smoking remains a major concern with a high preventive potential. In societies with a high prevalence of smoking, such as Switzerland $(>30 \%)$, large fractions of diseases may be prevented. However, from a policy making and ethical perspective, involuntary environmental exposures must be judged differently and separately. The example shows that the involuntary exposure of the entire population to ambient air pollution contributes considerably to chronic bronchitis symptoms. Abatement of air pollution and ETS have a similar preventive potential, given the current exposure patterns in Switzerland. However, in regions with much higher air pollution levels, the health relevance of air pollution may greatly increase.

Table 4 lists major areas of outdoor air pollution abatement strategies. The relative efficiency of these strategies may vary depending on local characteristics. However, in general, it is true that technological changes are more likely to be implemented, whereas, so far, politicians have often failed to support more comprehensive and efficient strategies. For example, the improvements in exhaust technology will, in the long term, neither improve air quality nor protect the health of the public if the growth rates in car selling and driving remain an unquestioned paradigm of "progress". Sustainable air pollution abatement must be more comprehensive and include, for example, urban planning with enforced public transport systems and rigorous promotion of low- or no-emission cars. From a health and prevention perspective, comprehensive traffic policies will be much more

Table 4. - Major air pollution abatement strategies

\begin{tabular}{|c|c|}
\hline Sector & Measure \\
\hline \multirow[t]{6}{*}{$\begin{array}{l}\text { General } \\
\text { policies }\end{array}$} & $\begin{array}{l}\text { Application of the "polluters pay } \\
\text { principle" }\end{array}$ \\
\hline & Energy/fuel pricing \\
\hline & Ecotaxes \\
\hline & Prioritise public transport systems \\
\hline & Urban planning \\
\hline & $\begin{array}{l}\text { "Marshal Plan" for renewable energies } \\
\text { to replace fossil fuel }\end{array}$ \\
\hline \multirow[t]{6}{*}{$\begin{array}{l}\text { Stationary } \\
\text { sources }\end{array}$} & $\begin{array}{l}\text { Emission control in industries, power } \\
\text { plants, incineration }\end{array}$ \\
\hline & Regulation of solvent use \\
\hline & Fuel production and distribution \\
\hline & $\begin{array}{l}\text { Coal, coke, oil reformulation for } \\
\text { power plants, industrial boilers, etc. }\end{array}$ \\
\hline & Modification in combustion processes \\
\hline & Closed circuit in dry cleaning \\
\hline \multirow[t]{5}{*}{$\begin{array}{l}\text { Mobile } \\
\text { sources }\end{array}$} & $\begin{array}{l}\text { Catalyst and particle filters for heavy } \\
\text { duty traffic, cars, trains, motorcycles, } \\
\text { off-road vehicles }\end{array}$ \\
\hline & Taxing kerosene for aircraft \\
\hline & Low- or no-emission engines \\
\hline & $\begin{array}{l}\text { Traffic regimens (car share, rush-hour } \\
\text { toll, etc.) }\end{array}$ \\
\hline & Fuel consumption-dependent taxes \\
\hline Products & $\begin{array}{l}\text { Solvent replacements in paints, } \\
\text { adhesives, etc. }\end{array}$ \\
\hline
\end{tabular}


efficient than the traditional selective policy approach [60].

In contrast to smoking, where individuals remain an important target of prevention, the examples in table 4 demonstrate that air pollution abatement requires policy decisions, regulations, technological and structural changes. Whereas individual reduction in smoking efficiently removes exposure, the individual has very little influence on outdoor air quality. Whereas personal health directly benefits from smoking reduction, individuals are unlikely to personally experience the health benefit of cleaner air. The health risks of ambient air pollution must be considered very small risks [58], on an individual level, thus, the minute personal contribution to air quality may have literally no personal health benefit. In addition, the air quality and public health benefits of clean air strategies will happen with some time lag which may be much longer than one election period. Thus, clean air policy makers face the very difficult challenge of finding majorities among decision makers to implement strategies which may cause costs or inconveniences but which will lead to little and most likely late benefits for the health of individuals. Nevertheless, the public health benefit of clean air policies are large, given the long-term everyday exposure of entire populations. In fact, the problem of small effects among individuals but large impact in the total population is a classic public health paradigm [61], and it has been shown that this apparent paradox is very relevant for air pollution and health [58]. Given the current level of scientific evidence, clinicians and all health professionals must contribute to inform decision makers about the long-term relevance of strong and sustained air pollution abatement. Although calculations of health costs due to air pollution are highly controversial, it must be emphasised that air pollution morbidity and mortality do occur, but are typically not paid for by the polluters. Thus, an important comprehensive clean air strategy will be the inclusion of external costs into polluting processes. The current low price model, for e.g. oil, gasoline or kerosene, does not cover the costs related to health damages due to air pollution.

\section{Will the health benefits of abatement happen?}

It is typically the case in environmental politics that stakeholders may question the need for and benefit of clean air policies. Thus, authorities may be asked to predict the long-term costs and benefits of regulations [20]. The question, thus, arises whether attributable cases as derived in the impact assessment truly reflect the number of cases that can be prevented under a clean air scenario. It must be acknowledged that such predictions inherently require further assumptions with additional levels of uncertainty and speculations. In fact, such studies may not add more than an "order-of-magnitude" idea about the distant future, and it remains inherently questionable whether it will ever be possible to rigorously and scientifically prove the long-term benefits of clean air strategies. At the least, long-term monitoring of both air pollution and health outcomes would be needed, in large populations. Given the long-term economic and cultural changes in societies, this will, however, not be enough to prove or disprove the long-term evidence. For instance, air quality may be improved but myocardial infarction may nevertheless increase, if smoking rates strongly increase. Such ecological comparisons are inherently flawed, thus, repeated full-scale epidemiological studies would be required to truly control confounding.

It must be emphasised that the health benefits may depend on the abatement strategy. Given that single pollutants may be surrogates for mixtures, highly pollutant-specific abatements may not yield the full range of health benefits. For more comprehensive strategies the question of the "culprit pollutant" is less relevant. For example, traffic-speed reductions or replacement of current car fleets with low- or noemission cars would reduce a variety of pollutants and, thus, optimise health benefits whatever the relative importance of single pollutants may be.

For short-term effects of air pollution, there is some preliminary empirical evidence that the health benefit of air quality improvements may happen within short periods of time. Although population-based experimental studies are usually not feasible in air pollution research, at least three "natural experiments" may be cited which are in line with rather prompt health benefits of improved air quality. The first is the "Utah Valley experience" where a 1-yr closure of a steel mill resulted in strong declines in air pollution, morbidity, and mortality. The reopening of the mill was accompanied by pollution and health rates climbing back to preclosure values [62]. As reported by HeINRICH et al. [63] the remarkable improvements in air quality in former East Germany were paralleled by a rather instant decline in respiratory symptom rates among children, which would be expected from the concentration risk function from a European epidemiological study [50]. The third "experiment" was undertaken during the Olympic games in Atlanta, GA, USA. Although it may be argued that such unusual events may limit the adequate consideration of confounding, the study shows that strong restrictions in inner-city car use was followed by reductions in air pollutants and a decrease in respiratory emergency room visits among children [64]. Although none of these studies can be conclusive, they are at least remarkably coherent with expectations under a scenario of causality. The studies suggest that shortterm effects may in fact be fully prevented if air pollutants are lower. It may be worthwhile to foresee or plan such "natural experiments" in advance to further assess the evidence of "accountability" of policies. Potential target regions for such "experiments" may be areas where large developing projects are just about to be implemented, such as the closure or opening of new and large traffic arteries or industrial facilities.

However, for long-term effects and benefits, the assessment may be much more difficult. In fact, due to competing risks and large-scale changes in exposure profiles, over long periods of time, air pollution attributable cases of long-term effects (e.g. mortality 
and chronic bronchitis among adults in the trinational study), may not be fully "preventable cases", or only many years after achieving better air quality [10]. This limitation of case attribution is not restricted to air pollution but also applies to the derivation of smoking attributable death, where it is generally assumed but impossible to prove that "attributable death" is at the same time "preventable death".

In the light of all the uncertainties and limitations, researchers should not lose sight of the general patterns and perspectives. Given the current level of evidence of the association between air pollution and health, the precautionary principle may provide excellent guide to rigorously implement clean air strategies. Horton [65] well described the precautionary principle as follows:

"We must act on facts, and on the most accurate interpretation of them, using the best scientific information. That does not mean that we must sit back until we have $100 \%$ evidence about everything. Where the state of the health of the people is at stake, the risks can be so high and the costs of corrective action so great, that prevention is better than cure. We must analyse the possible benefits and costs of action and inaction. Where there are significant risks of damage to the public health, we should be prepared to take action to diminish those risks, even when the scientific knowledge is not conclusive, if the balance of likely costs and benefits justifies it" [65].

Currently available impact assessment studies clearly suggest that public health largely benefits from better air quality. These studies are rather selective underestimates as they are strongly driven by mortality but do not fully include quantification of the impact on morbidity, and their consequences on quality of life among the diseased and the caregivers. It is also of note that key clean air strategies converge into abatement of climate change [66]. In general, energy consumption is very closely related to both air pollution and greenhouse gases. The dominant causes of both problems are the excessive and inefficient combustion of fossil fuel. Thus, for many policy options, the benefit of air pollution abatement will go far beyond what prudent health-impact assessments may derive. From a climate change and air pollution perspective, improved energy efficiency and a strong and decisive departure from the "fossil fuel" combustion society is a science-based must.

\section{Conclusion}

As discussed in this review, the methods to quantify the health impact of air pollution require assumptions and have to deal with inherent uncertainties. Prudent estimates of the impact confirm that even in regions with moderate pollution, compared with "hot spots" like the emerging mega-cities in the Far East, air pollution considerably contributes to morbidity and mortality throughout Europe. Abatement strategies are political in nature, thus, health professionals, such as clinicians, must raise their voices in the political decision process to give strong support for clean air policies, on both a national and an international level.

\section{References}

1. Maclure M. The case-crossover design: A method for studying transient effects on the risk of acute events. Am J Epidemiol 1991; 133: 144-153.

2. Liang K, Zeger S. Longitudinal data analysis using generalized linear models. Biometrika 1986; 73: 13-22.

3. Samet J, Dominici F, Curriero F, Coursac I, Zeger S. Fine particulate air pollution and mortality in 20 U.S. Cities 1987-1994. N Engl J Med 2000; 343: 17421749.

4. Katsouyanni K, Touloumi G, Spix C. Short-term effects of ambient sulphur dioxide and particulate matter on mortality in 12 European cities: results from times series data from the APHEA project. BMJ 1997; 314: 1658-1663.

5. Leuenberger P, Schwartz J, Ackermann-Liebrich U, and the Swiss Study on Air Pollution and Lung Diseases (SAPALDIA) Team. Passive exposure to tobacco smoke and respiratory symptoms in adults. Am J Respir Crit Care Med 1994; 150: 1222-1228.

6. Zemp E, Elsasser S, Schindler C, et al., and the Swiss Study on Air Pollution and Lung Diseases (SAPALDIA) Team. Long-term ambient air pollution and chronic respiratory symptoms (SAPALDIA). Am J Respir Crit Care Med 1999; 159: 1257-1266.

7. Ackermann-Liebrich U, Leuenberger P, Schwartz J, et al., and the Swiss Study on Air Pollution and Lung Diseases (SAPALDIA) Team. Lung function and long-term exposure to air pollutants in Switzerland. Am J Respir Crit Care Med 1997; 155: 122-129.

8. Holgate S, Samet JM, Koren HS, Maynard RL. Air Pollution and Health. San Diego/London, Academic Press, 1999.

9. Sommer H, Künzli N, Seethaler R, et al. An impact assessment project of Austria, France and Switzerland. In: Ancillary Benefits and Costs of Greenhouse Gas Mitigation: Proceedings from an Expert Workshop. New York, Organisation for Economic Cooperation and Development, 2000; pp. 451-479.

10. Sommer H, Chanel O, Vergnaud J, Herry M, Sedlak $\mathrm{N}$, Seethaler R. Monetary valuation of road trafficrelated air pollution. Health costs due to road trafficrelated air pollution. An impact assessment project of Austria, France and Switzerland. 1999. Bern, Paris, Wien. Prepared for the Third World Health Organisation Ministerial Conference of Environment and Health, London, 1999.

11. Department of Health Ad-hoc Group. Economic appraisal of the health effects of air pollution. London, The Stationary Office, 1999.

12. Rothman KJ, Greenland S. Modern Epidemiology. Boston/Toronto, Lippincott-Raven, 1998.

13. Northridge ME. Public health methods - attributable risk as a link between causality and public health action. Am J Public Health 1995; 85: 1202-1203.

14. Krzyzanowski M. Methods for assessing the extent of exposure and effects of air pollution. Occup Environ Med 97: 54: 145-151.

15. Künzli N, Kaiser R, Medina S, et al. Public health impact of outdoor and traffic-related air pollution: A European assessment. Lancet 2000; 356: 795-801.

16. Künzli N, Medina S, Kaiser R, Quénel P, Horak FJ, Studnicka M. Assessment of air pollution attributable deaths: should we use time-series or cohort study based risk estimates? Am J Epidemiol 2001; 153: 10501055. 
17. Künzli N, Kaiser R, Medina S, Studnicka M, Oberfeld G, Horak F Jr. Air pollution attributable cases. Technical report on epidemiology. Health costs due to road traffic-related air pollution. An impact assessment project of Austria, France and Switzerland. Prepared for the Third Ministerial Conference on Environment and Health, London, 1999. Berne, Switzerland, Federal Department for Environment, Transport, Energy and Communications Bureau for Transport Studies, Switzerland, 1999.

18. Künzli N, Kaiser R, Seethaler R. Quantitative Risikoabschätzung - Luft. In: Wichmann SF, ed. Handbuch Umweltmedizin. Landsberg, EcoMed, 2001.

19. Filliger P, Puybonnieux-Texier V, Schneider J. PM10 population exposure technical report on air pollution. Health costs due to road traffic-related air pollution. An impact assessment project of Austria, France and Switzerland, 1999. Berne, Paris, Wien. Prepared for the Third World Health Organsiation Ministerial Conference of Environment and Health, London, 1999.

20. USA Environmental Protection Agency. Draft regulatory impact analysis. Control of air pollution from new motor vehicles: Tier 2 motor vehicle emissions standards and gasoline sulfur control requirements. Washington DC, USA Environmental Protection Agency, April 1999.

21. World Health Organisation Working Group. Evaluation and use of epidemiological evidence for environmental health risk assessment: World Health Organisation guideline document. Environ Health Perspect 2000; 108: 997-1002.

22. World Health Organisation. Quantification of the health effects of exposure to air pollution. A report of a World Health Organisation working group. Copenhagen, Denmark, World Health Organisation Regional Office for Europe, 2001.

23. World Health Organisation. Air quality guidelines for Europe. Copenhagen, Denmark, World Health Organisation Regional Office for Europe, 2000.

24. Hill AB. The environment and disease: association or causation? Proc Royal Soc Med 1965; 58: 295-300.

25. Bates D. Health indices of the adverse effects of air pollution: the question of coherence. Environ Res 1992; 59: 336-349.

26. Taubes G. Epidemiology faces its limits. The search for subtle links between diet, lifestyle, or environmental factors and disease is an unending source of fear - but often yields little certainty. Science 1995; 269: 164-169.

27. Kaiser J. Panel backs EPA and 'Six Cities' study. Science 2000; 289: 711.

28. Kaiser J. Evidence mounts that tiny particles can kill. Science 2000; 289: 22-23.

29. Krewski D. Reanalysis of the Harvard six cities study and the American Cancer Society study of particulate air pollution and mortality. Cambridge, Health Effects Institute, 2000.

30. Bates DV. Lines that connect: assessing the causality inference in the case of particulate pollution. Environ Health Perspect 2000; 108: 91-92.

31. Ostro B, Chestnut L. Assessing the health benefits of reducing particulate matter air pollution in the United States. Environ Res 1998; 76: 94-106.

32. Martuzzi M, Galassi C, Forastiere F, Ostro B, Bertollini R, and the ITARIA Study Group. http://www. euro.who.int/document/E75492.pdf. Health impact of outdoor particulate air pollution in Italian cities.
Internal Report. Rome, World Health Organisation, 2000. Accessed: April 302002.

33. Abbey D, Petersen F, Mills P, Beeson W. Long-term ambient concentrations of total suspended particulates, ozone, and sulfur dioxide and respiratory symptoms in a nonsmoking population. Arch Environ Health 1993; 48: 33-46.

34. Sommer $H$, Neuenschwander RE, Sommer $H$, Neuenschwander RE. Monetarisierung der verkehrsbedingten externen Gesundheitskosten. Synthesebericht. Bern, GS EVED Dienst für Gesamtverkehrsfragen GVF [Monetarisation of external health costs due to traffic related air pollution. Synthesis report. Secretary General of former DETR, Office for Traffic Issues], 1996.

35. USA Environmental Protection Agency. Guidance for conducting health risk assessment of chemical mixtures (external scientific peer review draft). Washington DC, USA Environmental Protection Agency, April 1999.

36. Sunyer J, Saez M, Murillo C, Castellsague JMF. Air pollution and emergency room admission for chronic obstructive pulmonary disease: A 5-year study. $\mathrm{Am}$ $J$ Epidemiol 1993; 137: 701-705.

37. Schwartz J. Air pollution and hospital admissions for heart disease in eight U.S. counties. Epidemiology 1999; 10: 17-22.

38. Schwartz J. The distributed lag between air pollution and daily deaths. Epidemiology 2000; 11: 320-326.

39. Sorlie P, Kannel W, O'Connor G. Mortality associated with respiratory function and symptoms in advanced age: The Framingham study. Am Rev Respir Dis 1989; 140: 379-384.

40. Dockery D, Pope A, Xu X, et al. An association between air pollution and mortality in six U.S. cities. N Engl J Med 1993; 329: 1753-1759.

41. Pope A, Thun M, Namboodiri M, et al. Particulate air pollution as a predictor of mortality in a prospective study of U.S. adults. Am J Respir Crit Care Med 1995; 151: 669-674.

42. Abbey D, Nishino N, McDonnell WF, et al. Longterm inhalable particles and other air pollutants related to mortality in nonsmokers. Am J Respir Crit Care Med 1999; 159: 373-382.

43. Hoek G, Fischer P, van den Brandt P, Goldbohm S, Brunekreef B. Estimation of long-term average exposure to outdoor air pollution for a cohort study on mortality. Epidemiology 2001; 12: S92.

44. Brunekreef B. Air pollution and life expectancy: is there a relation? Occup Environ Med 1997; 54: 781784.

45. Pope CI. Epidemiology of fine particulate air pollution and human health: biologic mechanisms and who's at risk? Environ Health Perspect 2000; 108: 713-723.

46. National Resources Defense Council. Breath taking. Premature mortality due to particulate air pollution in 239 American cities. San Francisco, National Resources Defense Council, 1996.

47. American Lung Association. Dollars and cents: the economic and health benefits of potential particulate matter reductions in the United States. American Lung Association, 1995.

48. Künzli N, Schwartz J, Leuenberger P, AckermannLiebrich U, and the Swiss Study on Air Pollution Lung Diseases (SAPALDIA) Team. Association of environmental tobacco smoke at work and forced 
expiratory lung function. Am J Respir Crit Care Med 1994; 149: A393.

49. Smith KR, Samet JM, Romieu I, Bruce N. Indoor air pollution in developing countries and acute lower respiratory infections in children. Thorax 2000; 55: 518-532.

50. Braun-Fahrländer C, Vuille J, Sennhauser F, et al. and the Swiss Study on Childhood Allergy and Respiratory Symptoms with respect to Air Pollution, Climate and Pollen (SCARPOL) Team. Respiratory health and long-term exposure to air pollutants in Swiss schoolchildren. Am J Respir Crit Care Med 1997; 155: 1042-1049.

51. Röösli M, Künzli N, Oglesby L, et al. Assessment of cancer risk from air pollution in the region of Basel, Switzerland. Epidemiology 2000; 11: S67.

52. Murray CLA. The Global Burden of Disease. Published on behalf of the World Health Organisation and the World Bank. Cambridge, Harvard School of Public Health, 1996.

53. Murray C, Lopez A. Global mortality, disability, and the contribution of risk factors: Global burden of disease study. Lancet 1997; 349: 1436-1442.

54. Murray J, Lopez A. On the comparable quantification of health risks: Lessons from the global burden of diesease study. Epidemiology 1999; 10: 594-605.

55. Hong C. Air pollution. In: Murray C, Lopez A, eds. Quantifying Global Health Risks: The Burden of Disease Attributable to Selected Risk Factors. Cambridge, Harvard University Press, 1996.

56. Schopper DPJ, Torres A, Cuende N, et al. Estimating the burden of disease in one Swiss canton: what do disability adjusted life years (DALY) tell us? Int J Epidemiol 2000; 29: 871-877.

57. Heldstab J, Künzle $\mathrm{T}$, de Haan $\mathrm{P}$, Keller A. Bundesamt für Umwelt, Wald und Landschaft (BUWAL) [Swiss Agency for the Environment,
Forest and Landscape]. Modellierung der PM10Belastung in der Schweiz. Berne, Switzerland, Bundesamt für Umwelt, Wald und Landschaft, 1999.

58. Künzli N, Ackermann-Liebrich U, Brändli $\mathrm{O}$, Tschopp J, Schindler C, Leuenberger $P$, and the SAPALDIA Team. Clinically 'small effects' of air pollution on FVC have large public health impact. Eur Respir J 2000; 15: 131-136.

59. Department of the Environment. Costs and benefits for the UK of complying with the EC national emissions ceilings and ozone directive and the UNECE multi-pollutant, multi-effect protocol. London, Department of Energy and Transport of the Regions, April 2000.

60. Dora C. A different route to health: implications of transport policies. BMJ 1999; 318: 1686-1689.

61. Rose G. Sick individuals and sick populations. Int J Epidemiol 1985; 14: 32-38.

62. Pope A 3rd. Respiratory disease associated with community air pollution and a steel mill, Utah Valley. Am J Public Health 1989; 79: 623-628.

63. Heinrich J, Hoelscher B, Wichmann HE. Decline of ambient air pollution and respiratory symptoms in children. Am J Respir Crit Care Med 2000; 161: 19301936.

64. Friedman MS, Powell KE, Hutwagner L, Graham LM, Teague WG. Impact of changes in transportation and commuting behaviors during the 1996 Summer Olympic Games in Atlanta on air quality and childhood asthma. JAMA 2001; 285: 897-905.

65. Horton R. The new new public health of risk and radical engagement. Lancet 1998; 352: 251-252.

66. Intergovernmental Panel on Climate Change Working Group on Public Health and Fossil-Fuel Combustion. Short-term improvements in public health from global-climate policies on fossil-fuel combustion: an interim report. Lancet 1997; 350: 1341-1348. 